\title{
微粒子分散系の大規模シシュレーションの実現
}

\section{Toward Large-Scale Simulations of Dispersions of Small Particles}

\section{2}

\section{研究代表者 京都大学大学院工学研究科化学工学専攻}

$$
\text { 准教授 山本 量 一 Ryoichi Yamamoto }
$$

共同研究者 京都大学大学院工学研究科化学工学専攻

博士後期課程 2 年 岩 下 拓 哉 Takuya Iwashita

We have developed a unique method for direct numerical simulations (DNS) of dense colloidal dispersions. This method enables us to compute the time evolutions of colloidal particles, ions, and host fluids simultaneously by solving Newton, advection-diffusion, and Navier-Stokes equations so that the electro-hydrodynamic couplings can be fully taken into account. The electrophoretic mobilities of charged spherical particles are calculated in several situations. The comparisons with approximation theories show quantitative agreements for dilute dispersions without any empirical parameters; however, our simulation predicts notable deviations in the case of dense dispersions. Recently, our DNS code was modified to take into account the effect of Brownian motions of the particles. The new code has been applied to several cases where coupling between hydrodynamic interaction and the thermal fluctuation becomes important. Striking examples include chain formations of likely charged particles due to the application of external electric fields and dynamics of chain conformations fluctuating in host fluids. We also observed clear tendency of the shear thickening behavior when we apply shear flow to dense colloidal dispersions. The origin of the thickening will be studied in future.

\section{研究目的}

本研究で対象とする微粒子分散系の場合, 溶媒を構 成する分子の大きさや運動の時間スケールは微粒子の それらより何桁も小さく, シミュレーションのスケー ルを前者にあわせると意味のある結果を得るまでには 天文学的な計算時間が必要になる。逆に微粒子の方に スケールをあわせると，今度は現実と乘離した仮想的 なモデルを用いざるを得ず，実際の物質との対応が希 薄になる。このようなマルチスケールの階層性こそが
微粒子分散系のシミュレーションを困難にしている最 大の要因であり，この問題を克服した新しいシミュレ ーション法の開発が望まれている。そこで我々はハイ ブリッド型分子動力学法を提唱し, 開発を行っている。 これまでの基礎研究の成果を踏まえ, 本研究により, より大規模・高精度のシミュレーションを実現し, 微 粒子分散系の研究の発展を目指す。 


\section{研究成果の概要}

\section{1. 序論}

シミュレーションの立場から見た微粒子分散系の特 殊性は，まず系の緩和時間の長さにある。代表的なコ ロイド分散系では，粒子の運動だけでなく周囲の流体 やイオン雲囲気による長距離相互作用のために大規模 な協調運動が起こり，微視的な時間スケール $\left(\sim 10^{-10}\right.$ 秒）とはかけ離れた $10^{2} \sim 10^{3}$ 秒にも達する緩和時間を 示す。コロイド分散系の長時間緩和現象は通常の分子 動力学シミュレーション等で解ける時間範囲（～10 秒）からかけ離れているので, 有効な粗視化モデルが 構築され，メソシミュレーションの手法が発達した。

本稿ではまず，最近我々が開発したメソスケールの シミュレーション手法と, 濃厚なコロイド系へのその 手法の応用について紹介する。具体的に扱う問題は, 代表的なソフトマターでありながらこれまで理論的な 解析の難しかった荷電コロイド系の電気泳動現象であ る。さらに, 最近最も価格比性能の高いマルチコア CPUを使用したシミュレーションプログラムの並列 化についても取り組んでいる。

\section{2. 計算方法}

微粒子・コロイド分散系のシミュレーションを行う 場合, 周りにある溶媒やイオンの自由度を何らかの形 であらわに取り扱うか，それをあきらめて微粒子のみ で閉じたモデルに還元するかの選択がある。後者の場 合, 数值的には簡単であるがモデルの妥当性に問題が 残る。前者がより正確なのは言うまでもないが，すべ ての自由度をミクロな粒子として取り扱うことは, 残 念ながら世界最速のスーパーコンピュータをもってし ても実現不可能である。コロイドだけを粒子として， 溶媒を連続体として扱うハイブリッドなモデル化がこ のような場合に有効である。溶媒の自由度は完全に消 去するのではなく, 連続体として粗視化したメソスケ ールの変数として取り扱う。この場合, コロイド粒子 と溶媒の相互作用を粒子界面での境界条件として与え ると数值計算の効率が悪く, 多粒子分散系の数值計算 が不可能となる。

これまでにも流体粒子法 ${ }^{1)}$ などのユニークな解決策 が提案されているが, 我々はコロイド粒子と溶媒の界 面に滑らかなプロファイル（Smoothed Profile）を用
いて連続的に取り扱うという単純なアイデイアでこの 困難を回避できることを示した。液晶溶媒に分散した 多数の粒子を対象とした世界で初めてのシミュレーシ ヨン 2) や, 流体力学相互作用を正確に計算する手法 の開発 ${ }^{3)}$ に成功している。我々の方法は適応の範囲 が大変広く, 水中の生体分子や界面が関与する問題, 機能性材料開発, マイクロ流体デバイスやマイクロラ ボ等の諸問題への応用が可能である。このようなメソ スケールの移動現象では流体のレイノルズ数が小さい ために，いわゆる乱流の効果は無視することが可能で ある。逆に熱や物質の拡散の効果が大きくなり, イオ ンの分布や分子の配向など溶媒の内部自由度の影響も 重要になる。多彩な現象が報告されているが, 理解は 進んでおらずシミュレーションによる解析が有効であ る。

最近行った拡張では, ナノ・マイクロスケールで無 視することができない熱摇らぎの効果を粒子へのラン ダム力として導入した。これによりブラウン運動と粒 子間の流体力学相互作用を同時に正しく考慮すること が可能となり, 本シミュレーション手法で解析可能な 系はさらに広がっている。

\section{3. 結果と考察}

電解質溶液中を電気泳動するコロイド粒子系への応 用結果を図 1 , 図 2 に示す。このシミュレーションで は, コロイド粒子, イオンの濃度場, 溶媒の流動場の

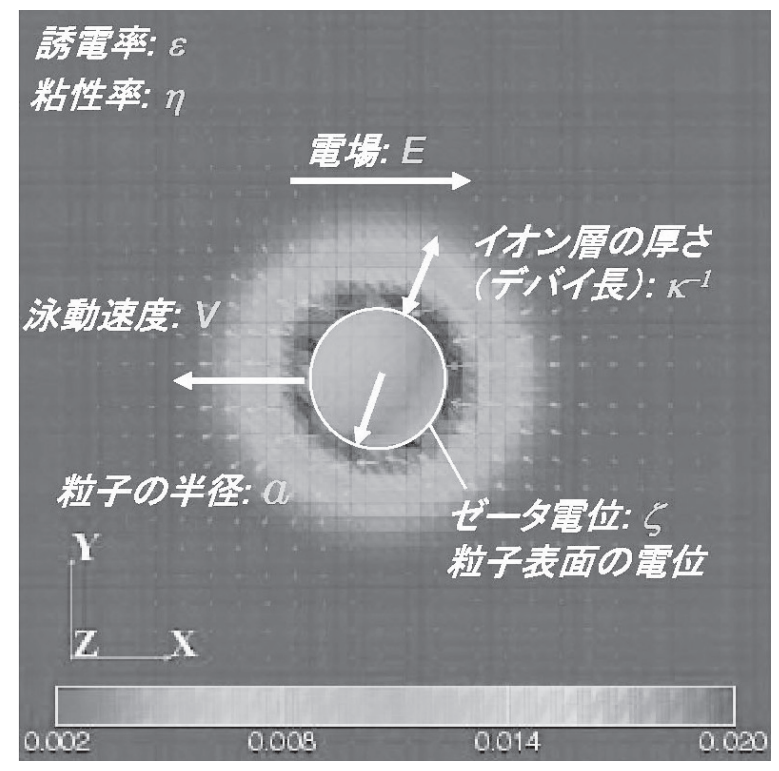

図 1 荷電コロイド粒子の電気泳動の直接シミュレー ションの概要 


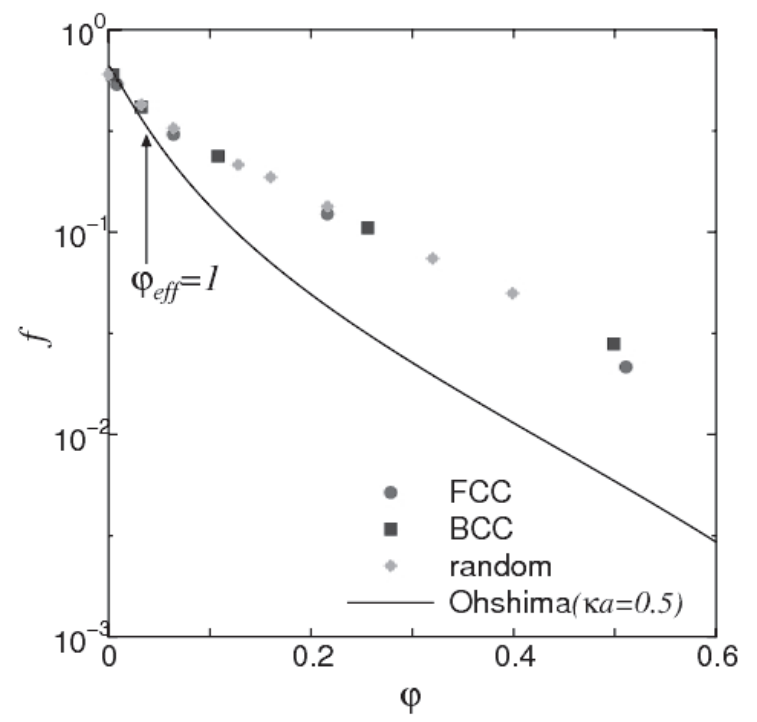

図 2 コロイド粒子分散系の電気泳動速度に対する体 積分率依存性。濃厚な領域では異なる粒子の電 気二重層の重なりが顕著になり，簡単なモデル 計算の結果から大きくずれる

3つの自由度をそれぞれの第一原理に基づいて扱って いる ${ }^{4)}$ 。印加する外部電場が弱いときには泳動速度 も遅く，イオンはコロイド粒子の周りにほぼ等方的に 分布しているが（図１），外部電場が大きくなると泳 動速度は早くなり，外部電場の効果と溶媒との摩擦の 2 つの効果により，イオンの分布は彗星が尾を引くよ うに非等方的になる。これによって生じる外部電場と 電気泳動速度との非線形性について詳細な解析を行な つた。また，世界で初めて多粒子電気泳動の定量的な シミュレーションに成功した（図２）。ここで用いた
シミュレーションプログラムは，フリーウエアとして WEBで公開されている ${ }^{5)}$ 。

最近では流体中に分散した微粒子のブラウン運動を 考慮するための拡張を行なった。その結果を図 3 に示 す ${ }^{6)}$ 。イオンのない微粒子と溶媒だけの単純な系で計 算を行い，自己速度相関関数の計算を行った。ここで 注目すべきは長時間領域での挙動であり，通常のラン ジュバン方程式から求まる指数減衰ではなく, 流体を 介した運動量輸送の効果に由来する $t^{-3 / 2}$ というべき則 で減衰する長時間テイルを示している。今回の拡張に よりブラウン運動と流体力学相互作用を正確に考慮し たシミュレーションを実現でき，両者の競合が重要な 役割を果たす微粒子分散系の幅広い問題への適用が可 能になった。

最後にシミュレーションプログラムの並列化につい て述べる。これまでのプログラムでは単一のCPUで の実行を念頭に置いていたため，取り扱える粒子の数 は最大で数百個程度であった。粒子の沈降や凝集など の問題をシミュレーションするには，より多くの粒子 数を扱う必要がある。最近インテル社などから相次い で発売されたマルチコアアーキテクチャーのCPUは 他の高性能CPUに比べて圧倒的に価格比性能に優れ ており，大規模シミュレーションを行なうための実行 環境として申し分ない。本研究では，これまでの単一 CPUのプログラムを基にして，シミュレーションの 並列化に取り組んだ。その結果，1 CPUに4コアあ るXeonプロセッサーを 2 個用いることで，単一CPU での実行に対して 6 倍の性能を引き出すことに成功し

\section{Velocity Correlation Function}
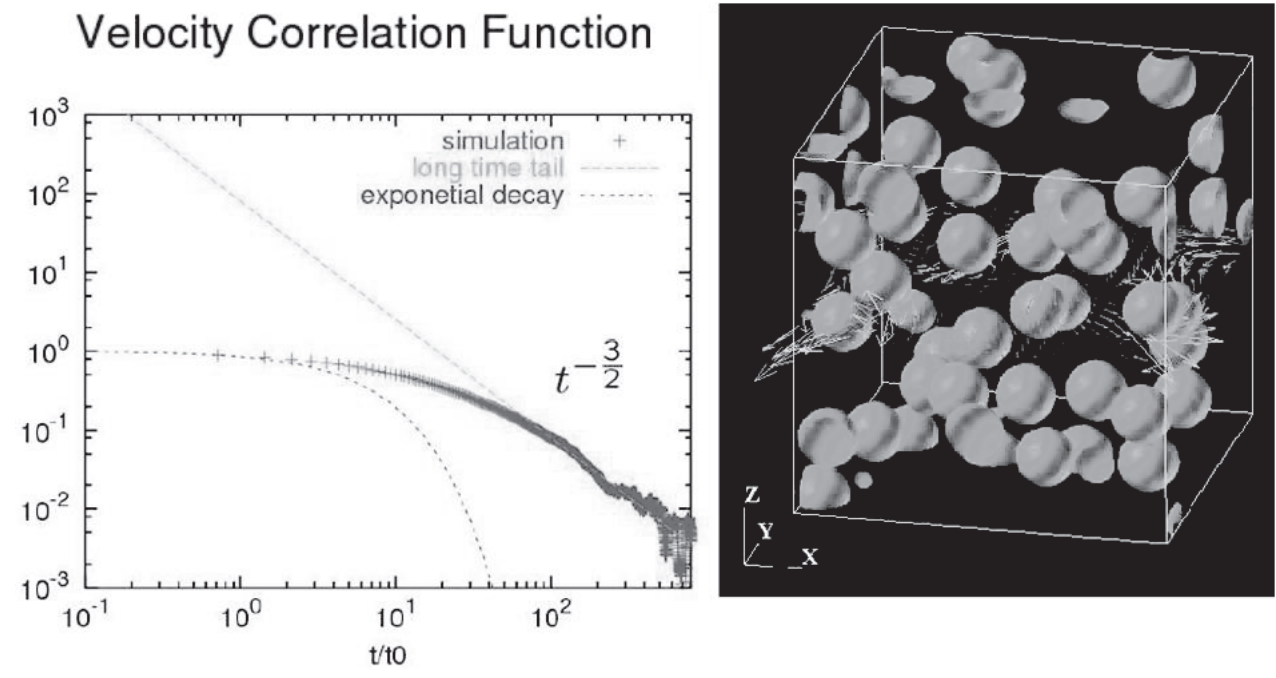

図 3 左：コロイド粒子の並進運動の自己速度相関関数。長時間側で流体力学的な挙動が 正しく再現されている。右：溶媒中で熱的に摇らいでいるコロイド粒子のスナップ ショット。矢印は溶媒の流速べクトルであり, 粒子の熱運動よって摇らいでいる 


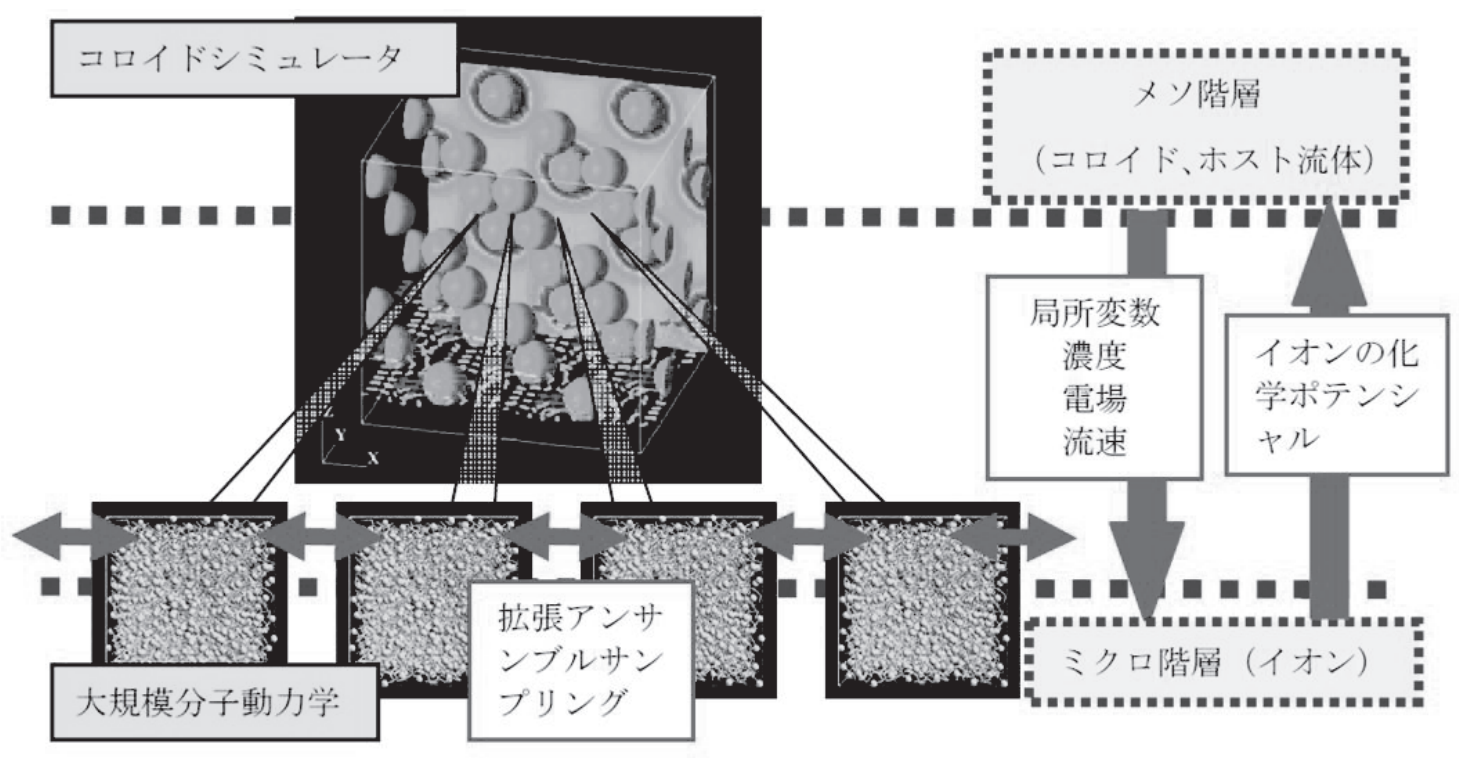

図：分子動力学法とコロイドシミュレーションの接続

図 4 荷電コロイド系のマルチスケールシミュレーションの概念図

ている。8コアCPUなど更なるマルチコア化が計画 されているので, 今後より大規模な微粒子分散系のシ ミュレーションに取り組むことが可能な状況となって いる。

\section{今後の研究の見通し}

ここまでのシミュレーションでは, ミクロ階層を統 計力学的な近似理論を用いてメソ階層に吸収してい る。しかしながら，このような近似理論による取り扱 いが難しい問題も多い。例えば多価イオンを含む電解 質溶液ではイオン強結合の状態が容易に実現し, 強く 相関した個々のイオンによりコロイド粒子間の相互作 用も大きな影響を受ける。場合によっては同一符号の 電荷を持つコロイド粒子間に静電引力が働くといった 奇妙な現象が起こるが，このような場合に有効な近似 理論はない。

我々は, メソ階層のシミュレーションにミクロな分 子動力学シミュレーションを接続することによって, この問題を根本から解決しようと考えている。図 4 の 様に自由度をイオンとコロイド・ホスト流体に分割 し，それぞれミクロとメソでモデルを与えることで統 計力学的に矛盾のない独自の手法の開発に着手してい $b^{7 \text { ) }}$ 。
参考文献

1) H. Tanaka and T. Araki, Phys. Rev. Lett. 85, 1338 (2000); H. Kodama, K. Takeshita, T. Araki, and H. Tanaka, J Phys.; Condens. Matt. 16, L115 (2004).

2 ) R. Yamamoto, Phys. Rev. Lett. 87, 075502 (2001); R. Yamamoto, Y. Nakayama, and K. Kim, J. Phys.; Condens. Matt. 16, S1945 (2004).

3 ) Y. Nakayama and R. Yamamoto, Phys. Rev. E 71, 036707 (2005); Y. Nakayama, K. Kim, and R. Yamamoto, cond-mat/0601322.

4 ) K. Kim, Y. Nakayama, and R. Yamamoto, Phys. Rev. Lett. 96, 208302 (2006)

5 ）荷電コロイド分散系シミュレータ：KAPSEL, http://www-tph.cheme.kyoto-u.ac.jp/kapsel/

6 ) T. Iwashita, Y. Nakayama, and R. Yamamoto, 準備中.

7 ) JST-CREST「ソフトマターの多階層/相互接続シミ ュレーション」, http://multiscale.jp/

\section{学会発表等}

1. 岩下拓哉, 名嘉山祥也, 山本量一, “微粒子分散系の直 接数值シミュレーション $[\mathrm{P}] ”$, 、ソトマター第 2 回 公開シンポジウム (名古屋) 2008/01/07-08.

2. Takuya Iwashita, Yasuya Nakayama and Ryoichi Yamamoto, "The velocity autocorrelation function of a Brownian particle by direct numerical simulation: Generalized Langevin equation and Long time tail $[\mathrm{P}]$ ", Symposium on the 50th Anniversary of the Alder transition kanazawa, 2007/11/29-30.

3 . 岩下拓哉, 名嘉山祥也, 山本量一, “ニュートン流体中 
に分散したブラウン粒子に対する付加質量の影響 [P]”, 日本機械学会 第20回計算力学講演会 CMD2007 (京都市) 2007/11/26-28.

4. 岩下拓哉, 名嘉山祥也, 山本量一, “非圧縮性ニュート ン流体中に分散したブラウン粒子に対する直接数值計 算手法 $[\mathrm{P}] ”$, 第 1 回ソフトマター物理若手勉強会（広 島県) 2007/08/27-29.

5 . 岩下拓哉, 名嘉山祥也, 山本量一, “新しい直接数值計 算法による高分子鎖の緩和ダイナミクス”，第12回高 分子計算機科学討論会 (滋賀県) 2007/08/9-10.

6. Ryoichi Yamamoto, Takuya Iwashita, Kang Kim, and Yasuya Nakayama, "Direct Numerical Simulations of Colloidal Dispersions under External Fields", The YITP workshop on "New Frontiers in Colloidal Physics: A Bridge between Micro- and Macroscpic Concepts in Soft Matter" (Kyoto, Japan) 2007/07/25-27.

7. Ryoichi Yamamoto, Takuya Iwashita, Kang Kim, and Yasuya Nakayama, "Direct Numerical Simulations of Colloidal Dispersions under External Fields" [P], Soft, Complex, and Biological Matter Conference (SOCOBIM-2007): Satellite Conference of IUPAP Statphys 23 (Terrasini, Sicily, Italy) 2007/07/15-19.

8. 山本量一 “外場下のコロイド分散系の直接数值計算” $[\mathrm{P}]$ ，科研費特定領域研究「非平衡ソフトマター物理 学の創成：メソスコピック系の構造とダイナミクス」 第 2 回領域研究会（米沢市）2007/06/21-23.

9. 岩下拓哉, 山本量一, “ブラウン運動を考慮したナノス ケール微粒子系の新しい直接数值計算手法”，粉体工 学会2007春季研究発表会 (東京都) 2007/05/22-23.

10. 岩下拓哉, 山本量一, 名嘉山祥也, “流体力学相互作用 を考慮したブラウン運動する微粒子の直接数值計算” [P]，日本レオロジー学会2007第34回年会（京都市） 2007/05/14-15

11. 岩下拓哉, 山本量一, 名嘉山祥也, “流体力学相互作用 を考慮した高分子鎖のダイナミクス”，日本物理学会 2007春季大会（鹿児島市）2007/03/18-21

12. 山本量一, 岩下拓哉, 名嘉山祥也, “熱摇らぎと流体力 学相互作用を考慮した微粒子分散系のシミュレーショ ン”，化学工学会第72年会（京都市）2007/03/19.

13. 山本量一, “ソフトマターのマルチスケールシミュレ ーションを目指して”[招待講演，第 5 回北大シミュ レーションサロン (HSS) ワークショップ（札幌市） 2007/03/16

14. 岩下拓哉, 山本量一, 名嘉山祥也, “熱摇らぎと流体力 学相互作用を考慮した高分子鎖の緩和シミュレーショ ン”，ソフトマター第一回公開シンポジウム(東京) 2007/03/15-16
15. 山本量一, “ソフトマターの計算機シミュレーション” [特別セッション招待講演], 東京大学物性研究所短期 研究会「計算物性科学に扔けるスーパーコンピュータ 利用の現状と展望」(千葉県柏市） 2006/12/12.

\section{発表論文}

1. Ryoichi Yamamoto, Kim kang, and Yasuya Nakayama, Strict simulations of non-equilibrium dynamics of colloids, Colloids and Surfaces A: Physicochemical and Engineering Aspects, 311, 42-47 (2007).

2. Ryoichi Yamamoto, Kim kang, and Yasuya Nakayama, KAPSEL: Kyoto Advanced Particle Simulator for ELectrohydrodynamics-Toward Direct Numerical Simulations of Colloidal Dispersions-, KONA, 24, 167-182 (2006).

3. Kang Kim, Yasuya Nakayama and Ryoichi Yamamoto, Direct Numerical Simulations of Electrophoresis, Phys. Rev. Lett., 96, 208302 (2006).

4. Kang Kim, Yasuya Nakayama and Ryoichi Yamamoto, Simulating electrohydrodynamics in charged colloidal dispersions: A smoothed profile method, AIP Conference Proceedings, 832, 251-256 (2006).

5. Yasuya Nakayama, Kang Kim and Ryoichi Yamamoto, Hydrodynamic effects in colloidal dispersions studied by a new efficient direct simulation, AIP Conference Proceedings, 832, 245-250 (2006).

6. 山本量一

荷電コロイド分散系の計算機シミュレーション セラミックス, 43, 77-86 (2008).

7. 山本量一 コロイド系のハイブリッドシミュレーション 高分子, 56, 1001 (2007).

8. 山本量一, 米谷慎, 奥薗透, 福田順一 液晶の計算機シミュレーション

液晶, 11, 259-266 (2007).

9. 名嘉山祥也, 金鋼, 山本量一

コロイド分散系の直接数值シミュレーション ケミカルエンジニヤリング, 52, 340-345 (2007).

10. 名嘉山祥也, 金鋼, 山本量一 Smoothed Profile 法によるコロイド系の直接数值シミ ユレーション＼cjkstart粉体工学会誌, 44, 191-197 (2007).

11. 金鋼, 名嘉山祥也, 山本量一 荷電コロイド分散系の直接数值シミュレーションー KAPSELの原理と操作一粉体工学会誌, 44, 28-36 (2007). 